\title{
Towards a more comprehensive modelling of the behaviour of transuranic elements in agricultural soils: Experimental procedure for the study of the sorption/desorption parameters and speciation of transuranic actinides in the rhizosphere
}

\author{
T. Perrier, A. Martin-Garin, C. Leyval ${ }^{1}$ and C. Mustin ${ }^{1}$ \\ Instifut de Profection et de Süreté Nucléaire, Laboratoire de Radioécologie Expérimentale, \\ CE Cadarache, BP. 1, 13108 Saint-Paul-lez-Durance cedex, France \\ 1 Centre de Pédologie Biologique, UPR 6831 du CNRS \\ associée a I'Université Henri Poincaré-Nancy I, 17 rue Notre-Dame des Pauvres, \\ $B P .5,54501$ Vandouvre-lès-Nancy cedex, France
}

\begin{abstract}
The present paper describes the experimental on-going program on the biogeochemical behaviour of americium and neptunium in the thizosphere of agricultural soils. Investigation is made by column experiments under close-to-natural conditions, supported by complementary batch experiments. Columns filled with $2 \mathrm{~mm}$-sieved soil, contaminated with ${ }^{24 i} \mathrm{Am}$ or ${ }^{23} \mathrm{~Np}$, are leached by soil solutions of varying compositions including citric acid and/or glucose. The outlet solution is analyzed ( $\mathrm{pH}$, Eh, conductivity, major tons, low molecular weight organic acids, radionuclides) and ultrafiltration is used to determine the relation between particle size and cactivity. The objective of the study is to ascertain quantitative information on the effects of root exudates, of the physico-chemical parameters of the soil solution as well as the potential role of microorganisms, on the sorption/desorption processes and the speciation in solution ${ }^{241} \mathrm{Am}$ and ${ }^{237} \mathrm{~Np}$.
\end{abstract}

\section{INTRODUCTION}

Americium and neptumium are two radionuclides artificially produced during the nuclear fuel cycle. Because of their high radiotoxicity and long half-life ${ }^{241} \mathrm{Am}$ and ${ }^{237} \mathrm{~Np}$ are some of the most problematic radiopollutants for the environment. It is of cardinal importance to understand their fate in soils, and especially in the vegetated top soil layer under the influence of plant roots, called herein "rhizosphere". That corresponds to the first zone exposed to superficial contamination. For those radionuclides the bioavailability to plants and therefore possible human contamination through the food chain, as well as the subsurface migration leading to groundwater contamination, depend on their biogeochemical behaviour in this soil layer. The behaviour of actinides in terms of sorption/desorption properties, speciation and migration have been well studied in the context of deep nuclear waste repositories $[1,2]$. Within this framework the role of colloids and organic matter (humic acids) in the complexation and migration of actinides in groundwater/geological media have been clearly demonstrated [3, 4]. Similar observations have been evidenced in subsurface aquifer systems [5] and ought to apply to the rhizosphere, as a porous media containing organic matter, though it has not yet been studied. Little is known about the behaviour of actinides in soils [6] and even less in the rhizosphere. The influence of root exudates and associated microorganisms on the remobilization of actinides is a poorly studied question. Organic acids generated in the rhizosphere by soil microorganisms and plant roots enhanced the leaching of $\mathrm{Zn}$ from heavy-metal contaminated mine tailings $[7,8,9]$. Furthermore, the complexing properties of citric acid on actinides have been reckoned in leaching tests of contaminated surface soils for remediation technology studies [10]. Therefore, the objective of this research is to evaluate the fate of ${ }^{24 !} \mathrm{Am}$ and ${ }^{237} \mathrm{~Np}$ in the rhizosphere by analyzing the interactions between plant roots, soil, soil solution and microflora. Leaching tests are performed over a range of percolation solutions spiked with citric acid and glucose in columns filled with natural soil contaminated by actinides. The liquid/solid interactions are studied as well as the actinide speciation in the outlet solution, the alteration of the contamination profile in the column and the reaction kinetic rates. Parallel batch experiments are set up to determine the influence of microflora and quantify the sorption/desorption phenomena $\left(\mathrm{K}_{\mathrm{d}}\right)$. Sterilized experiments (columns and batch experiments) are planned to investigate the effect of microbial influence on the behaviour of ${ }^{24 !} \mathrm{Am}$ and

${ }^{23} \mathrm{~Np}$. Experiments in cultivated pots are foreseen to study in situ remobilization of the two actinides. The chosen plant model is the rye-grass Lolium perenne $L$. . With its active and dense root hair, it allows to make the hypothesis of an homogeneous impact of root exudates on the whole top soil layer. 


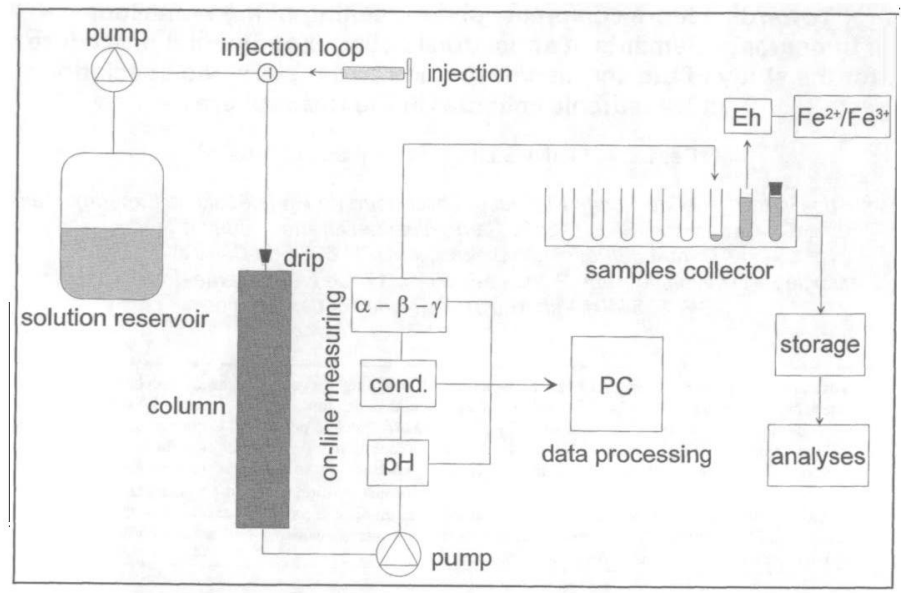

Figure 1: Experimental setup for column experiments (unsaturated column design shown)

\section{OVERVIEW OF THE EXPERIMENTAL PROCEDURE}

\subsection{Soils}

A natural soil is used in the experiments to get the most close-to-natural conditions. The soil was sampled in France in October 2000. The upper organic layer was removed and the twenty centimeters of the A horizon were collected. Long-term storage is done in a dark cold room at $+7^{\circ} \mathrm{C}$. Before use the soil is sieved at $2 \mathrm{~mm}$ and air-dried with storage at room temperature. It is moistened and subsequently contaminated in successive layers by actinides [11]. The soil is chosen among three different types of agricultural soils. It corresponds to the most reproducible porous media in terms of hydraulic properties (stability in columns, permeability at saturation, handling ease, ...) and biological characteristics (number, type and activity of microorganisms).

\subsection{Artificial soil solution}

The solution used in our study is an artificial soil solution with the same inorganic composition (pH, ionic strength, major jons) as the natural solution in equilibrium with the soil. Different solutions are made from this standard solution. Citric acid and/or glucose are added in this standard solution to simulate the rhizospheric conditions. Citric acid is one of the main organic acids released by roots and microorganisms [12] and is one of the strongest complexing agent both for actinides and iron, a chemical analogue of americium $[10,11,13]$. Glucose is the simplest sugar, the most easily assimilable by microorganisms. It is used in the experiments as an activating agent of microbial activity. Two concentrations are used in the experiments among the highly variable (both in time and space) exudates concentrations found in the rhizosphere $[12,14,15,16]: 10^{-4} \mathrm{M}$, a typical mean concentration $[17,18]$ of rhizosphere environment and $10^{-2} \mathrm{M}$ [19], a high concentration that should bring effective complexation and leaching, particularly for ${ }^{241} \mathrm{Am}[10]$. 


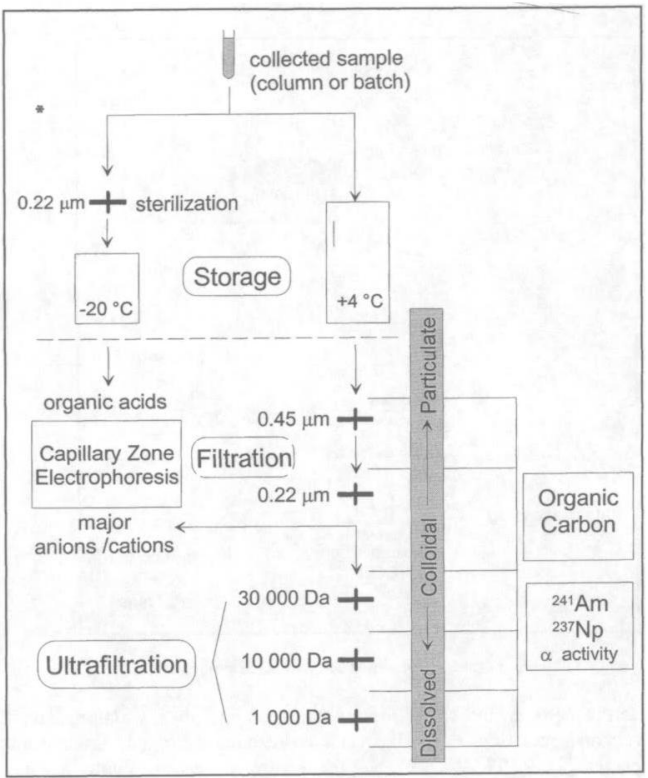

Figure 2: Simplified diagram of the storage and analytical line

\subsection{Columns}

Saturated and unsaturated columns are used to scan different moisture content and consequently different biogeochemical processes. Unsaturated columns reproduce a triphasic media (soil-soil solution-air) wel] representative of the superficial zone of soils with its associated aerobic microbial activity. Saturated columns reproduce a diphasic media where aerobic and anaerobic biological processes depend anong others on flow velocity. Columns are packed with contaminated soil and leached for about a month with the different percolation solutions. The experimental setup is shown in Fig.1. Tritiated water (HTO) is used as a conservative tracer to determine the hydraulic properties of columns. The breakthrough curves of HTO are measured using flow through monitors for $\beta$ and $\gamma$ radiation. The radiation of ${ }^{241} A m$ is possibly measured by the same equipment if the concentrations are sufficient. Conductivity and $\mathrm{pH}$ are monitored on-line and the samples are collected. Redox potential and iron oxidation state are immediately determined before chemical equilibrium with atmosphere. Samples are then stored prior to analysis.

\subsection{Storage and analytical procedures}

The storage and analytical line are shown in Fig.2. Collected samples are split in two aliquots. The fraction dedicated to organic acids analysis is sterilized on a $0.22 \mu \mathrm{m}$ polycarbonate filter and frozen according to Karlsson et al. [20]. The fraction dedicated to ultrafiltration is stored in the dark at $+4^{\circ} \mathrm{C}$. Capillary zone electrophoresis is used to analyze the major organic acids $[21,22,23,24,25]$ as well as the major ions $\left(\mathrm{K}^{+}, \mathrm{Na}^{+}, \mathrm{Ca}^{2+}, \mathrm{Mg}^{2+}, \mathrm{Cl}^{-}, \mathrm{PO}_{4}{ }^{2}, \mathrm{SO}_{4}{ }^{2-}, \mathrm{CO}_{3}{ }^{2-}\right)$ of the soil solution [26]. A filtration and ultrafiltration line $(0.45 \mu \mathrm{m}, 0.22 \mu \mathrm{m}, 30000 \mathrm{Da}, 10000 \mathrm{Da}$ et $1000 \mathrm{Da})$ is used to determine organic 


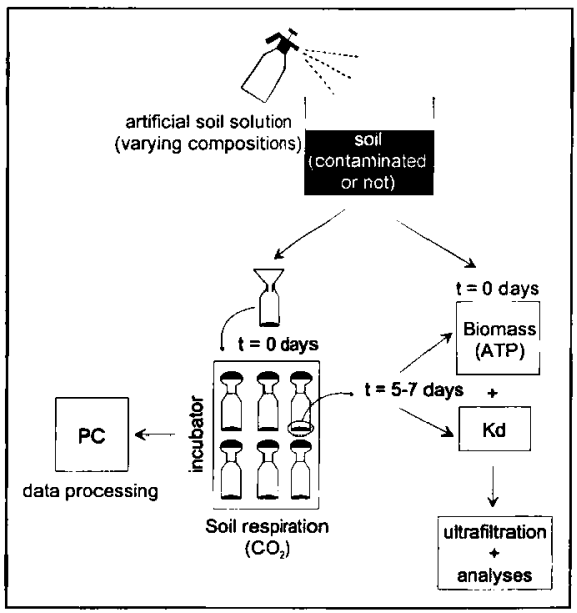

Figure 3: Simplified setup of batch experiments

carbon and radioactive activity for each filtrate corresponding to a fraction size. Semi-quantitative information is given on speciation, each size class corresponding to particular organic and inorganic complexes and species [2, 4, 27, 28, 29]. At the ending of each column leaching, a counting of radioactive activity is made on soil slices to determine the final contamination profile, either by scanning or by standard methods after freezing of the column and slicing. The percentage of desorbed activity is thus quantified.

\subsection{Batch experiments}

Microbial processes that may occur in columns are investigated in closed vial experiments called batches (Fig. 3). The toxic effect of actinides, the activating effect of glucose, the effect of temperature and moisture content on microbial biomass and activity are observed. The estimation of biomass is done by ATP measurement $[30,31,32,33]$. The global activity of microorganisms is measured by their respiration. The $\mathrm{WTW}^{\mathrm{TM}}$ Oxitop ${ }^{2}$ design is used which monitors the resulting depression in oxygen in the closed vial, the released $\mathrm{CO}_{2}$ being trapped in sodium hydroxyde. From the same samples, sorption/desorption parameters $\left(K_{d}\right)$ of ${ }^{241} \mathrm{Am}$ and ${ }^{237} \mathrm{~Np}$ are measured both in saturated and unsaturated conditions (Fig. 3) [11].

\subsection{Modelling}

Geochemical modeling is used to predict the speciation of the elements and check the experimental results. The models used are CHESS, MINEQL+ and PHREEQC. Models are unfortunately very poor in thermo-dynamic constants for organic species even if some constants exist for humic acids-actinides complexes $[2,27,29]$. Experimental results and geochemical modeling should allow to identify and quantify the major parameters (physical, chemical or biological) and help to build an operational model using for example a parameterized equilibrium coefficient $K_{d}$. 


\section{CONCLUSION AND PERSPECTIVES}

In the end the whole range of experiments will give complete information on the chemistry of the soil solution, semi-quantitative information on the speciation of the two actinides, a quantification of their desorption as well as an overview of the influence of soil microorganisms under monitored hydrodynamic and kinetic conditions. This information will be integrated in coupled models including biogeochemical, hydrodynamic and kinetic processes. Sensitive analysis will define the key parameters controlling the behaviour of ${ }^{24 !} \mathrm{Am}$ and ${ }^{237} \mathrm{~Np}$ in the rhizosphere. The most consistent data will then be simplified to be integrated in assessment models. Furthemore, the knowledge acquired on the availability and possible mobility of actinides in the rhizosphere will be used in further studies related to soil-to-plant transfers.

\section{References}

[1] J. I. Kim, D. S. Rhee, and G. Buckau. Radiochim. Acta, 52/53(1-2) (1991) 49-55.

[2] C. Marquardt. Final Report FZKA 6557, Forschungszentrum Karlsruhe (2000).

[3] J. I. Kim, B. Delakowitz, P. Zeh, D. Klotz, and D. Lazik. Radiochim. Acta, 66-67 (1994) 165-171.

[4] R. Artinger, B. Kienzler, W. Schuessler, and J. I. Kim. J. Contam. Hydrol, 35 (1998) 261-275.

[5] J. F. MeCarthy, K. R. Czerwinski, W. E. Sanford, P. M. Jardine, and J. D. Marsh. J. Contam. Hydrol., 30(1-2) (1998) 49-77.

[6] S. Roussel-Debet. Technical Report IPSN/DPRE/SERLAB 99/019, IPSN (1999).

[7] M.K. Banks, A. Schwab, G. R. Fleming, and B. A. Hetrick. Chemosphere, 29(8) (1994) 1691-1699.

[8] M.K. Banks, C. Y. Waters, and A. Schwab. J. Environ. Sci. Health., A29(5) (1994) 1045-1056.

[9] S.R. Burckhard, A. P. Schwab, and M.K. Banks. J. Hazard. Mater., 41 (1995) 135-145.

[10] N. Lu, K. S. Kung, C. F. V. Mason, I. R. Triay, C. R. Cotter, A. J. Pappas, and M. E. G. Pappas. Environ. Sci. Technol., 32(3) (1998) 370-374.

[11] S Roussel-Debet, C. Colle, P. Hurtevent, and M. Morello. Radioprotection, 35(4) (2000) 505-518.

[12] P. Hinsinger. Advances in Agronomy, 64 (1998) 225-265.

[13] R. Villarreal and D. Spall. Technical Report LA-UR 97-3407, Los Alamos National Laboratory (1995).

[14] E. A. Curl and B. Truelove. The rhizosphere. (Springer Verlag, Heidelberg, 1986).

[15] P. Lemanceau and T. Heulin. Sol interface fragile edited by P. Stengel. (INRA, 1998).

[16] J. M. Gobat, M. Aragno, and W. Matthey. Le sol Vivant. (Presses Polytechniques et Universitaires Romandes, Lausanne, 1998).

[17] D. L. Jones and P. R. Darrah. Plant Soil, 166 (1994) 247-257.

[18] D. L. Jones. Plant Soil, 205(1) (1998) 25-44.

[19] B. S. Griffiths, K. Ritz, N. Ebblewhite, and G. Dobson. Soil Biol. Biochem., 31 (1999) 145-153.

[20] S. Karlsson, H. Wolrath, and J. Dahlen. Water Res., 33(11) (1999) 2569-2578.

[21] Z. L. Chen, C. Tang, and J. C. Yu. J. High Res. Chrom., 22(7) (1999) 379-385.

[22] A. Göttlein and R. Blasek. Soil Sci., 161 (1996) 705-715.

[23] B. W. Strobel, I. Bernhoft, and O. K. Borggaard. Plant Soil, 212(2) (1999) 115-121.

[24] C. Barbas, J. A. Lucas Garcia, and F. J. Gutierrez Manero. Phytochem. Analysis, 10 (1999) 55-59.

[25] B. W. Strobel. Geoderma, 99 (2001) 169-198.

[26] B. Westergaard, H. C. B. Hansen, and O. K. Borggaard. Analyst, 123 (1998) $721-724$.

[27] J. I. Kim, G. Buckau, R. Klenze, D. S. Rhee, and H. Wimmer. Final Report Nucl. Sci. Tech. EUR13181, Commission of the European Communities (1991).

[28] G. Buckau. Final report FZKA 6324, Forschungszentrum Karlsruhe (1999).

[29] K. R. Czerwinski, Valerie Moulin, C. Marquardt, A. Dierckx, and G. Bidoglio. Final Report Nucl.

Sci. Tech. EUR 16843 EN, Comission of the European Communities (1996).

[30] P. Davet. Vie microbienne du sol et production végétale. (INRA Editions, 2000).

[31] K. Alef. Methods in applied sol microbiology and biochemistry. (Academic Press, London, 1995).

[32] M. Contin, A. Todd, and P. C. Brookes. Soil Biol. Biochem., 33(4-5) (2001) 701-704.

[33] R. Martens. Soil Biol. Biochem., 33(8-9) (2001) 973-982. 